IGCS20_1257

\section{ADENOCARCINOMA IN SITU OF THE CERVIX - EVALUATION OF PATIENTS WITH CONSERVATIVE TREATMENT IN SOUTHERN BRAZIL}

J Hoefel* ${ }^{*}$. João Pedro P. Hoefel, Brazil

10.1136/ijgc-2020-IGCS.212

Objective To evaluate conservative treatment in patients with a diagnosis of adenocarcinoma in situ (AIS) patients in Southern Brazil.

Methods/Materials A retrospective cohort study of patients diagnosed with AIS between 2002 and 2019. Clinical characteristics and pathologic information including specimen volume, margin status, treatment type, pregnancy and oncologic outcomes were collected.

Results The mean age was 39.7 years $(S D \pm 9.4)$. The initial treatment performed was loop electrosurgical excision procedure (LEEP) in seven $(21,2 \%)$ participants, cold-knifecone $(\mathrm{CKC})$ in 26 (78.8\%). After the conization, 18 women underwent conservative management, three patients (3/18) became pregnant once and another two patients (2/ 18) went to hysterectomy in the follow-up. Residual lesion was noted in 7 (41\%) hysterectomy specimens, with 2 cases of adenocarcinoma. In our study, an inverse association was found between the volume of the surgical specimen (in $\mathrm{mm} 3$ ) in the LEEP procedure $(\mathrm{p}=0.033)$ and the positive surgical margin $(\mathrm{p}=0.012)$. There was no association between the treatment performed, the volume of the surgical specimen, and recurrence with negative or positive margins ( $p>0.05$ ).

Conclusion Conservative treatment is an option in the treatment of AIS, for patients who desire fertility-sparing treatment. Conservative management with LEEP is associated with higher positive margin rates than $\mathrm{CKC}$, however outcomes were similar when margins are negative. The specimen volume was not associated with recurrence.
IGCS20_1258

\section{THE EXPERIENCE IN PELVIC EXENTERATION IN PATIENTS WITH ADVANCED AND RECURRENT CERVICAL CANCER IN BELARUS}

O Matylevich*, O Sukonko, L Mirilenko. NN Alexandrov National Cancer Center, Belarus

\subsection{6/ijgc-2020-IGCS.213}

Objective To determine the efficacy of pelvic exenteration (PE) in patients with locally advanced, persistent and recurrent cervical cancer (CC).

Methods A retrospective study was performed of 30 patients with locally advanced, persistent and recurrent CC who underwent PE in 2006-2012. Anterior PE was performed in $24(80 \%)$ patients, posterior PE in $2(7 \%)$ and total PE in $4(13 \%)$.

Results The mean operation time was $279.5 \mathrm{~min}$. Urine derivation in 28 patients was performed in the following ways: 7 (25\%) patients were subjected to ureterostomy, 21 (75\%) had plastic interventions for neocyst formation. Fecal diversion performed in 5 patients by end colostomy (Hartman's procedure) and in one patient rectum resection was performed.

Radical surgery was performed in $70 \%$ (21 of 30 ) of the patients.

The median follow-up time of the 28 patients was 76.3 months. During the follow-up period, 19 (68\%) patients died of the underlying disease with no deaths of other causes. The median survival was 15.5 months, 5-year survival - 32\% (SE $8.8 \%$ ). The median survival after radical surgery was 37.9 months vs 5.5 months after nonradical one. Five-year causespecific survival after radical surgery was 74\% (SE 10.1\%; 95\% CI 49-91\%), after nonradical one - 33\% (SE 15.7\%).

Conclusion Surgical radicality has been established to be a clinically and statistically significant factor of death risk: the radical surgery enables to reduce the death risk 3.5 -fold $(95 \%$ CI 1.4-9.0; $\mathrm{p}=0.009)$, to increase the median survival 6.9 fold, 5-year survival from $11 \%(\mathrm{SE} 10.5 \%)$ to $42 \%$ (SE $11.3 \%, 95 \%$ CI 20-67\%).

\begin{tabular}{|c|c|c|c|c|c|c|c|c|}
\hline & \multicolumn{2}{|c|}{ Specimen volume $\left(m^{3}\right)$} & \multicolumn{2}{|c|}{ LEEP } & \multicolumn{2}{|c|}{ Positive margins } & \multicolumn{2}{|c|}{ Recurrence } \\
\hline & Is & p-value & Is & p-yalue & Is & p-yalue & Is & p-yalue \\
\hline Specimen Volume $\left(\mathrm{mm}^{3}\right)$ & NA & NA & $-0,371$ & 0,033 & $-0,382$ & 0,012 & 0,135 & 0,395 \\
\hline LEEP & $-0,371$ & 0,033 & NA & NA & 0,048 & 0,779 & $-0,170$ & 0,315 \\
\hline Positive margins & $-0,382$ & 0,012 & 0,048 & 0,779 & NA & NA & 0,078 & 0,569 \\
\hline Resurrences & 0,135 & 0,394 & $-0,170$ & 0,315 & 0,078 & 0,569 & NA & NA \\
\hline
\end{tabular}

LEEP - Loop Electrosurgical Excision Procedure. rs - Spearman's correlation coefficient. NA - not applicable. Spearman correlations. Volume of surgical specimen $n=42(75.0 \%)$. Procedure performed $n=56(100.0 \%)$. Surgical specimen margin $n=56(100.0 \%)$. Recurrence $n=11(19.7 \%)$. Significance set at $5 \%$ for all analyzes. Numbers highlighted in bold showed relationships between variables. 